\title{
Factors Affecting Ultrasonographic Fetal Weight Estimation Accuracy in Low Birth Weight Newborns
}

\author{
Nevin TUTEN', Onur GURALP2 ${ }^{2}$ Koray GOK³, Abdullah TUTEN ${ }^{4}$, Altay GEZER ${ }^{4}$ \\ Istanbul, Turkey
}

\section{ABSTRACT}

OBJECTIVE: To investigate the accuracy of fetal weight estimation made by the last prenatal ultrasound measurement in low birth weight newborns $(<2500 \mathrm{~g})$.

STUDY DESIGN: A total of 1082 women were evaluated in this retrospective cohort study. Demographic and clinical information of the mother and newborn and obstetric ultrasonography measurements and findings performed in the last week before birth were recorded. Accuracy of fetal weight estimation and parameters affecting it was investigated.

RESULTS: Accurate estimation rates were lower in the term compared to the preterm delivery group; and in the SGA group compared to the AGA group (respectively, $p=0.016, p=0.032$ ). Accurate estimation rates $(p=0.182)$ were comparable between the $500-1500 \mathrm{~g}$ and $1501-2500 \mathrm{~g}$ subgroups. The multiple linear regression analysis showed that gestational age at birth, birth weight, examination during labor, and duration between examination to delivery were statistically significant for the accurate estimation $(p=0.001)$

CONCLUSIONS: Accurate estimation rates were lower in the term compared to the preterm delivery group, and in the SGA group compared to the AGA group. The factors affecting accurate estimation were found to be gestational age at birth, birth weight, examination during labor, and duration between examination to delivery.

Keywords: Accurate estimation rate, Duration between examination to delivery, Examination during labor, Gestational age at birth, Low birth weight newborn

\section{Gynecol Obstet Reprod Med 2022;28(1):23-30}

${ }^{1}$ Kanuni Sultan Suleyman Education and Research Hospital, Obstetrics and Gynecology Istanbul, Turkey

${ }^{2}$ Carl von Ossietzky Oldenburg University, University Hospital for Gynecology and Obstetrics, Klinikum Oldenburg AoR, Oldenburg, Germany

3 Sakarya University, Education and Research Hospital, Obstetrics and Gynecology, Sakarya, Turkey

${ }^{4}$ Istanbul University-Cerrahpasa, Cerrahpasa Medical Faculty, Department of Obstetrics and Gynecology, Istanbul, Turkey

Address of Correspondence: Abdullah Tuten

Istanbul University-Cerrahpasa,

Cerrahpasa Medical Faculty, Department

of Obstetrics and Gynecology,

Cerrahpasa 34098 Fatih Istanbul, Turkey

drabdtuten@gmail.com

Submitted for Publication: 09.10.2020 Revised for Publication: 15.10.2020 Accepted for Publication: 12.03.2021 Online Published: 11.04.2021

ORCID IDs of the authors: OG: 0000-0002-3517-3046,

AT: 0000-0002-8495-6426,

NT: 0000-0001-8609-4770

$K G$ : 0000-0002-7420-1484

$A G$ : 0000-0003-4884-7780

\begin{tabular}{|c|c}
\hline Quick Response Code: & Access this article online \\
\cline { 2 - 2 } & $\begin{array}{l}\text { Website: www.gorm.com.tr } \\
\text { e- mail: info@gorm.com.tr }\end{array}$ \\
\cline { 2 - 2 } & DOI:10.21613/GORM.2021.1157 \\
\hline
\end{tabular}

How to cite this article: Tuten N. Guralp O. Gok K. Tuten A. Gezer A. Factors Affecting Ultrasonographic Fetal Weight Estimation Accuracy in Low Birth Weight Newborns. Gynecol Obstet Reprod Med. 2022;28(1):23-30

\section{Introduction}

Fetal growth and developmental follow-up are a standard part of antenatal care. The importance of fetal growth and developmental follow-up derives from its capacity to detect high and low birth weight fetuses that could cause negative perinatal impacts early enough and provide appropriate antenatal management opportunities accordingly. Especially in the presence of low birth weight fetus, as the weight percentile according to gestational age decreases, perinatal morbidity and mortality risk increases $(1,2)$. The fact that low birth weight fetuses suffer from these complications is because of both prematurity and intrauterine growth deficiency. In other words, fetal growth, growth restriction, and its rate are determinant in terms of increasing the risk of perinatal complications; detecting these abnormalities early enough will help the physician in deciding how the gestation, delivery, and newborn after birth will be managed.

Fetal weight estimation is calculated by applying various biometric indicators measured by ultrasonography into different formulas. In general, a combination of biparietal diameter (BPD), head circumference (HC), abdominal circumference (AC), and femur length (FL) measurements are in these for- 
mulas. More than thirty formulas on fetal weight estimation have been published. The most used ones are Warsof (3), Shephard (4), and Hadlock $(5,6)$ formulas.

The error rate in fetal weight estimation by ultrasonography is low for fetuses that have term and normal birth weight whereas it is high for fetuses that are non-term (pre-term, postterm) and do not have normal birth weight (SGA and LGA) (7). Whether the baby is term as well as several maternal, fatal, and natal factors birth weight according to gestational week may be determinant in the error rate.

This study aims to present the accuracy of fetal weight estimation measured by the last ultrasonography before delivery in low birth weight $(<2500$ gr) newborns in determining the real birth weight as well as these variables.

\section{Material and Method}

The patients' documents of all singleton pregnancies delivered in the Obstetrics and Gynecology Department of Istanbul University-Cerrahpasa, Cerrahpasa Medical Faculty between 01.01.2008 and 31.12.2014 were retrospectively evaluated in this cohort study. The inclusion criteria included singleton pregnancies with a small for gestational age (SGA) fetus (birthweight $<2500 \mathrm{~g}$ ) and delivery between $24+0$ and $41+0$ gestational week $(\mathrm{GW})$. The exclusion criteria included congenital anomalies, multiple gestations, and a duration of more than 7 days between ultrasound examination and delivery. A total of 1082 cases were included according to these criteria. This study was authorized by the Ethics Committee of the Istanbul University-Cerrahpasa, Cerrahpasa Medical Faculty (06.11.2014, 02-235911). Consent to use the data was obtained for this retrospective study, and the study was conducted in accordance with Helsinki's Declaration.

Maternal age, body mass index (BMI), use of tobacco, maternal systemic diseases, number of pregnancies and deliveries, concomitant pregnancy complications such as preeclampsia, gestational diabetes, presence of preterm rupture of membranes, and ultrasonographic measurements and findings in several weeks before delivery such as biparietal diameter (BPD), head circumference (HC), abdominal circumference (AC), femur length (FL), estimated fetal weight (EFW), amniotic fluid index, fetal presentation, fetal gender, and placental insertion site, birth weight, and 1 and 5 minutes APGAR scores were recorded. Ultrasonographic examinations were performed by obstetrics residents with similar experience with the Sonoscape SSI 5000 Ultrasound (China). The Hadlock I formula $(\log 10$ weight $=1.35960 .00386 \mathrm{AC} 9 \mathrm{FL}+0.0064 \mathrm{HC}$ $+0.00061 \mathrm{BPD} 9 \mathrm{AC}+0.0424 \mathrm{AC}+0.174 \mathrm{FL}$ ) was used to calculate the fetal weight.

Preterm delivery was defined as birth $<37+0 \mathrm{GW}$, and term delivery was defined as $>37+0 \mathrm{GW}$. SGA was defined as an estimated fetal weight of $<10$ percentile and large for gestational age (LGA) was defined as an estimated fetal weight of $>90$ percentile. The SGA newborns were further divided into 500$1500 \mathrm{~g}, 1501-2500 \mathrm{~g}$ subgroups according to the birthweights.

Maternal BMI was defined as body weight in $\mathrm{kg} / \mathrm{height}$ $(\mathrm{m})^{2}$.

The absolute percentage error was calculated as: (| the actual birth weight - estimated fetal weight/the actual birth weight) $\times 100$.

All cases were divided into accurate and inaccurate estimation groups. The accurate and inaccurate estimation groups included the cases with absolute deviation rates of $<10 \%$ and $\geq 10 \%$, respectively.

\section{Statistical analysis}

All parameters were entered into the database in the Statistical Package for the Social Sciences (SPSS) software version 20.0 (SPSS Inc., Chicago, IL). The KolmogorovSmirnov test was used to assess the distribution of the continuous variables. The homogeneous parametric variables were presented as mean \pm standard deviation (SD) and non-homogeneous continuous variables were presented as median (minimum-maximum). The comparison between the preterm and term subgroups was carried out with T-Test and MannWhitney-U test for the homogeneous and non-homogeneous parametric variables, respectively. Categorical variables were compared with the Chi-square test. A linear regression analysis was performed to evaluate the factors which may influence the absolute percentage error. A p-value of $<0.05$ was accepted as statistically significant.

\section{Results}

A total of 1082 women, 822 with preterm and 260 with term pregnancy were included in the statistical evaluation. Maternal age, gravidity, parity, BMI, frequencies of maternal systemic disorders, use of tobacco were comparable between the preterm and term pregnancies. Mean gestational age at delivery was $33.41 \pm 3.82$ weeks considering all women, $32.01 \pm 3.31$ weeks in preterm, and $37.82 \pm 0.83$ weeks in term pregnancies $(p=0.001)$. The frequencies of preeclampsia development $(p=0.001)$ and premature rupture of membranes ( $p=0.001)$ were significantly higher in the preterm delivery group compared to the term delivery group. Spontaneous vaginal delivery was more frequent in the term delivery group ( $p=0.001$ ). $52.7 \%$ of all newborns were female. In the term delivery group, the rate of female newborns was significantly higher than the preterm delivery group ( $58.8 \%$ vs $50.7 \%$, respectively, $p=0.023$ ). Mean birth weight was $1759.38 \pm 592.16$ g. Mean birth weight were $1595.02 \pm 581.02$ and $2279.02 \pm 191.42$ in the preterm and term delivery groups, respectively $(p=0.001)$. One and five minute APGAR scores were significantly higher in the term delivery group than the preterm delivery group ( $p=0.001$ and $p=0.001$ ) (Table I) 
Table I: Maternal and fetal demographic and clinical features in the preterm and term delivery groups

\begin{tabular}{|c|c|c|c|c|}
\hline & All patients & Preterm & Term & $p$ \\
\hline Age (years) & $30.09 \pm 5.74$ & $29.94 \pm 5.79$ & $30.53 \pm 5.58$ & 0.151 \\
\hline BMI $\left(\mathrm{kg} / \mathrm{m}^{2}\right)$ & $28.46 \pm 4.83$ & $28.49 \pm 4.95$ & $28.36 \pm 4.45$ & 0.715 \\
\hline Tobacco use $(\mathrm{n} / \mathrm{N}),(\%)$ & $147 / 1082(13.6 \%)$ & $110 / 822(13.4 \%)$ & $37 / 260(14.2 \%)$ & 0.728 \\
\hline Maternal systemic diseases $(\mathrm{n} / \mathrm{N}),(\%)$ & $458 / 1082(42.3 \%)$ & $339 / 822(41.2 \%)$ & $119 / 260(45.8 \%)$ & 0.854 \\
\hline Gravidity $(n)$ & $2.43 \pm 1.60$ & $2.2 \pm 1.5$ & $2.4 \pm 1.6$ & 0.205 \\
\hline Parity (n) & $0.85 \pm 1.07$ & $0.7 \pm 1.0$ & $0.8 \pm 1.0$ & 0.503 \\
\hline Development of preeclampsia $(\mathrm{n} / \mathrm{N}),(\%)$ & $403 / 1082(37.2 \%)$ & $359 / 822(43.7 \%)$ & $44 / 260(16.9 \%)$ & $0.001^{*}$ \\
\hline $\operatorname{PROM}(\mathrm{n} / \mathrm{N}),(\%)$ & $155 / 1082(14.3 \%)$ & $152 / 822(18.5 \%)$ & $3 / 260(1.2 \%)$ & $0.001^{*}$ \\
\hline Gestational age at birth (weeks) & $33.41 \pm 3.82$ & $32.01 \pm 3.31$ & $37.82 \pm 0.83$ & $0.001^{*}$ \\
\hline Examination after the onset of labor $(\mathrm{n} / \mathrm{N}),(\%)$ & $358 / 1082(33.1 \%)$ & $242 / 822(29.4 \%)$ & $116 / 260(44.6 \%)$ & $0.001^{*}$ \\
\hline Birth weight (Mean \pm SD, g) & $1759.38 \pm 592.16$ & $1595.02 \pm 581.02$ & $2279.02 \pm 191.42$ & $0.001^{*}$ \\
\hline Female gender (n/N), (\%) & $570 / 1082(52.7 \%)$ & $417 / 822(50.7 \%)$ & $153 / 260(58.8 \%)$ & $0.023^{*}$ \\
\hline 1 min APGAR score (Mean \pm SD) & $5.82 \pm 2.00$ & $5.48 \pm 2.04$ & $6.90 \pm 1.39$ & $0.001^{*}$ \\
\hline 5 min APGAR score (Mean $\pm S D)$ & $7.54 \pm 1.62$ & $7.27 \pm 1.69$ & $8.40 \pm 0.94$ & $0.001^{*}$ \\
\hline
\end{tabular}

BMI: Body-mass-index, PROM: Premature rupture of membranes, SD: Standard deviation. ${ }^{*} p<0.05$ is statistically significant

The frequencies of the fetal presentation types (head, breech, transverse, foot) were comparable between the groups ( $p=0.118$ ). Amniotic fluid volume was normal in $45.9 \%$ of the pregnancies in the term pregnancy group and $56.5 \%$ of the pregnancies in the preterm delivery group. Oligohydramnios rates were $49.1 \%$ and $41.5 \%$ in the preterm and term delivery groups, respectively. Anhydramnios rates were $2.1 \%$ and $0.4 \%$ in the preterm and term delivery groups, respectively. Polyhydramnios rates were $2.6 \%$ and $1.5 \%$ in the preterm and term delivery groups, respectively. The amniotic fluid volume rates were significantly different among the groups ( $p=0.009$ ). The placental insertion sites (fundus, anterior, posterior, and praevia) and adhesion defects (accreta, increta) were comparable between the groups $(p=0.699)$ (Table II).
Percentage error $(p=0.001)$ and absolute percentage error $(p=0.001)$ were higher and accurate estimation rates $(p=0.016)$ were lower in the term compared to the preterm delivery group. Percentage error $(p=0.001)$ and absolute percentage error $(p=0.015)$ were higher and accurate estimation rates ( $p=0.032$ ) were lower in the SGA group compared to the AGA group. Percentage error $(p=0.215)$, absolute percentage ( $p=0.139)$, and accurate estimation rates $(p=0.182)$ were comparable between the 500-1500 $\mathrm{g}$ and 1501-2500 g subgroups (Table III).

The linear regression analysis with the dependent variable accurate estimation showed that birth weight $(\mathrm{p}=0.001$, $\left.\mathrm{R}^{2}=0.902\right)$, GA at delivery $\left(p=0.001, \mathrm{R}^{2}=0.769\right)$, examination during labor ( $\left.p=0.001, \mathrm{R}^{2}=0.107\right)$, duration between examina-

Table II: Comparison of fetal presentation, amniotic fluid volume state, and placental location, and adhesion abnormalities in the preterm and term delivery groups

\begin{tabular}{|c|c|c|c|c|c|}
\hline & & Total & Preterm & Term & $p$ \\
\hline \multirow{5}{*}{$\begin{array}{l}\text { Fetal } \\
\text { presentation }\end{array}$} & Head $(\mathrm{n} / \mathrm{N}),(\%)$ & $787 / 1082(72.7 \%)$ & $583 / 822(70.9 \%)$ & $204 / 260(78.5 \%)$ & \multirow{5}{*}{0.118} \\
\hline & Breech $(n / N),(\%)$ & $243 / 1082(22.5 \%)$ & $195 / 822(23.7 \%)$ & $48 / 260(18.5 \%)$ & \\
\hline & Transverse $(\mathrm{n} / \mathrm{N}),(\%)$ & $40 / 1082(3.7 \%)$ & $35 / 822(4.3 \%)$ & $5 / 260(1.9 \%)$ & \\
\hline & Oblique $(n / N),(\%)$ & $6 / 1082(0.6 \%)$ & $4 / 822(0.4 \%)$ & $2 / 260(0.8 \%)$ & \\
\hline & Foot $(\mathrm{n} / \mathrm{N}),(\%)$ & $6 / 1082(0.6 \%)$ & $5 / 822(0.5 \%)$ & $1 / 260(0.4 \%)$ & \\
\hline \multirow{4}{*}{$\begin{array}{l}\text { Amniotic } \\
\text { fluid volume } \\
\text { state }\end{array}$} & Normal (n/N), (\%) & $524 / 1082(48.4 \%)$ & $377 / 822(45.9 \%)$ & $147 / 260(56.5 \%)$ & \multirow{4}{*}{$0.009^{*}$} \\
\hline & Oligohydramnios (n/N), (\%) & $515 / 1082(47.6 \%)$ & $407 / 822(49.5 \%)$ & $108 / 260(41.5 \%)$ & \\
\hline & Polyhydramnios (n/N), (\%) & $25 / 1082(2.3 \%)$ & $21 / 822(2.6 \%)$ & $4 / 260(1.5 \%)$ & \\
\hline & Anhydramnios (n/N), (\%) & $19 / 1082(1.7 \%)$ & $17 / 822(2.1 \%)$ & $1 / 260(0.4 \%)$ & \\
\hline \multirow{6}{*}{$\begin{array}{l}\text { Placental } \\
\text { site and } \\
\text { insertion } \\
\text { abnormalities }\end{array}$} & Fundus (n/N), (\%) & $134 / 1082(12.4 \%)$ & $101 / 822(12.3 \%)$ & $33 / 260(12.7 \%)$ & \multirow{6}{*}{0.699} \\
\hline & Anterior wall (n/N), (\%) & $486 / 1082(44.9 \%)$ & $370 / 822(45.0 \%)$ & $116 / 260(44.6 \%)$ & \\
\hline & Posterior wall (n/N), (\%) & 279/1082 (25.8\%) & $207 / 822(25.2 \%)$ & $72 / 260(27.7 \%)$ & \\
\hline & Side wall $(\mathrm{n} / \mathrm{N}),(\%)$ & $141 / 1082(13.0 \%)$ & $108 / 822(13.1 \%)$ & $33 / 260(12.7 \%)$ & \\
\hline & Placenta previa $(\mathrm{n} / \mathrm{N}),(\%)$ & $38 / 1082(3.5 \%)$ & $33 / 822(4.0 \%)$ & $5 / 260(1.9 \%)$ & \\
\hline & Placenta insertion abnormality $(\mathrm{n} / \mathrm{N}),(\%)$ & $4 / 1082(0.4 \%)$ & $3 / 822(0.4 \%)$ & $1 / 260(0.4 \%)$ & \\
\hline
\end{tabular}

${ }^{*} p<0.05$ is statistically significant 
Table III: Comparisons of the percentage error, absolute percentage error, and accurate estimation rates between the preterm and term groups; AGA and SGA fetuses' groups; birth weight $500-1500 \mathrm{~g}$ and $1501-2500 \mathrm{~g}$ groups

\begin{tabular}{|c|c|c|c|c|c|c|}
\hline & $\begin{array}{l}\text { Median percentage error } \\
\text { (min-max }\end{array}$ & $\mathbf{p}^{1}$ & $\begin{array}{l}\text { Median absolute percentage error } \\
\qquad(\min -\max )\end{array}$ & $p^{2}$ & $\begin{array}{l}\text { Accurate estimation } \\
\qquad(\mathrm{n} / \mathrm{N}, \%)\end{array}$ & $p^{3}$ \\
\hline Preterm & $\begin{array}{c}-3.30 \\
(-46.36-(43.38))\end{array}$ & \multirow[b]{2}{*}{$0.001^{*}$} & $\begin{array}{c}8.86 \\
(0-(46.36))\end{array}$ & \multirow[b]{2}{*}{$0.001^{*}$} & $\begin{array}{l}527 / 822 \\
(64.1 \%)\end{array}$ & \multirow[b]{2}{*}{$0.016^{*}$} \\
\hline Term & $\begin{array}{c}-8.11 \\
(-49.52-(20.44))\end{array}$ & & $\begin{array}{c}10.59 \\
(0-(49.52))\end{array}$ & & $\begin{array}{l}145 / 260 \\
(55.8 \%)\end{array}$ & \\
\hline AGA & $\begin{array}{c}-1.49 \\
(-41.18-(38.36))\end{array}$ & \multirow[b]{2}{*}{$0.001^{*}$} & $\begin{array}{c}8.79 \\
(0-(41.18))\end{array}$ & \multirow[b]{2}{*}{$0.015^{*}$} & $\begin{array}{l}264 / 398 \\
(66.3 \%)\end{array}$ & \multirow[b]{2}{*}{$0.032^{*}$} \\
\hline SGA & $\begin{array}{c}-6.40 \\
(-49.52-(43.38))\end{array}$ & & $\begin{array}{c}9.72 \\
(0-(49.52))\end{array}$ & & $\begin{array}{l}408 / 684 \\
(59.6 \%)\end{array}$ & \\
\hline $\begin{array}{l}\text { Birth weight } \\
(500-1500 \mathrm{~g})\end{array}$ & $\begin{array}{c}-3.39 \\
(-46.36-(29.00))\end{array}$ & \multirow[b]{2}{*}{0.215} & $\begin{array}{c}9.85 \\
(0-(46.36))\end{array}$ & \multirow[b]{2}{*}{0.139} & $\begin{array}{l}218 / 363 \\
(60.05 \%)\end{array}$ & \multirow[b]{2}{*}{0.182} \\
\hline $\begin{array}{l}\text { Birth weight } \\
(1501-2500 \mathrm{~g})\end{array}$ & $\begin{array}{c}-4.70 \\
(-49.52-(43.38))\end{array}$ & & $\begin{array}{c}8.98 \\
(0-(49.52))\end{array}$ & & $\begin{array}{l}459 / 719 \\
(63.83 \%)\end{array}$ & \\
\hline
\end{tabular}

${ }^{*} p<0.05$ is statistically significant

tion to delivery ( $p=0.001, \mathrm{R}^{2}=0.049$ ), amniotic fluid volume state $\left(p=0.001, \mathrm{R}^{2}=0.036\right)$, fetal presentation $(p=0.001$, $\left.\mathrm{R}^{2}=0.021\right)$, and presence of premature rupture of membranes ( $p=0.003, \mathrm{R}^{2}=0.004$ ) were significant. BMI, fetal gender, and placental location were not significant $(p>0.05)$ (Table IV).

The multiple linear regression analysis showed that gesta- tional age at birth, birth weight, examination during labor, and duration between examination to delivery was statistically significant ( $p=0.001)$; whereas amniotic fluid volume state, fetal presentation, and presence of premature rupture of membranes were not significant for the prediction of the accurate estimation $(p>0.05)$. The $\mathrm{R}^{2}$ was 0.929 for the significant parameters in the multiple linear regression analysis (Table V).

Table IV: Linear regression analysis of the parameters which may affect fetal weight estimation accuracy

\begin{tabular}{llll}
\hline & $\mathbf{R}^{\mathbf{2}}$ & $\boldsymbol{p}$ & $\mathbf{9 5} \% \mathbf{C l}$ \\
\hline Body-mass-index & 0.001 & 0.256 & $-3.398 / 12.730$ \\
Fetal gender & 0.001 & 0.643 & $-96.586 / 59.627$ \\
Gestational age at birth & 0.769 & $0.001^{*}$ & $144.788 / 154.578$ \\
Birth weight & 0.902 & $0.001^{*}$ & $1.028 / 1.069$ \\
Premature rupture of membranes & 0.004 & $0.030^{*}$ & $-234.418 /-12.253$ \\
Fetal Presentation & 0.021 & $0.001^{*}$ & $124.501 / 297.836$ \\
Placenta localization & 0.001 & 0.625 & $-58.859 / 97.940$ \\
Amniotic fluid volume state & 0.036 & $0.001^{*}$ & $169.671 / 322.895$ \\
Examination after onset of labor & 0.107 & $0.001^{*}$ & $375.092 / 531.776$ \\
Duration between examination and delivery & 0.049 & $0.001^{*}$ & $-100.300 /-58.409$ \\
\hline
\end{tabular}

${ }^{*} p<0.05$ is statistically significant

Table V: Multiple regression analysis of the parameters which may affect fetal weight estimation accuracy

\begin{tabular}{|c|c|c|c|c|}
\hline & $p$ & $95 \% \mathrm{Cl}$ & $\mathbf{R}^{2}$ & $p$ \\
\hline Gestational age at birth & $0.001^{*}$ & $26.920 / 39.265$ & & \\
\hline Birth weight & $0.001^{*}$ & $0.782 / 0.864$ & & \\
\hline Premature rupture of membranes & 0.696 & $-40.911 / 27.326$ & & \\
\hline Fetal presentation & 0.664 & $-28.916 / 18.443$ & 0.929 & $0.001^{*}$ \\
\hline Amniotic fluid volume state & 0.060 & $-0.916 / 45.016$ & & \\
\hline Examination after the onset of labor & $0.001^{*}$ & $70.055 / 117.442$ & & \\
\hline Duration between examination and delivery & $0.001^{*}$ & $-48.291 /-36.665$ & & \\
\hline
\end{tabular}

${ }^{*} p<0.05$ is statistically significant 


\section{Discussion}

This study had the following maternal and fetal conclusions: development of preeclampsia and early membrane rupture is more frequently observed in the preterm delivery group whereas spontaneous labor was more frequent in the term delivery group. This situation may be due to the earlier iatrogenic birth induction in the preterm delivery group due to the maternal and fetal indications before the onset of spontaneous labor. The rates of oligohydramnios and anhydramnios in the preterm group are higher than in the term group. A possible reason behind this is that the development of anhydramnios and oligohydramnios due to both premature membrane rupture and uteroplacental insufficiency are more frequent in the preterm group. In the term delivery group, it was found that babies' APGAR scores at 1 and 5 minutes after birth were higher compared to the preterm group because it was most likely in preterm births to suffer from intrauterine fetal problem secondary to uteroplacental insufficiency than in term births due to underdevelopment and less maturation.

Since fetal weight estimation is an important factor in predicting possible morbidity and mortality and deciding on intervention, the accuracy of fetal weight estimation is of the utmost importance. Several methods have been used in fetal weight estimation until today. Among these methods, the most often used and the most accurate one is ultrasonography. Nevertheless, it is not possible to calculate fetal weight via ultrasonography with $100 \%$ accuracy. There are many factors affecting the accuracy of ultrasonographic weight estimation (8).

The accuracy of fetal weight estimation by ultrasonography has been discussed in several studies since the introduction of fetal biometric measurements. It is rather difficult to measure birth weight at the upper and lower percentiles of fetal weight. To overcome this problem, special measurement models have been developed for fetuses with SGA and LGA. Although there have not been many studies on newborns with SGA, it has been concluded that the chances of error rate in preterm gestation regarding fetal weight estimation by ultrasonography are higher than in term gestation. This error rate is higher in newborns with SGA (7).

Several formulas are used in fetal weight estimation by ultrasonography. Among these, the most commonly used one is the Hadlock formula (9). The Hadlock formula was used in our study whereas a special formula was not used for those with SGA. The differences in the error rate percentage, the absolute error rate percentage, and the accuracy rate between SGA and AGA groups were consistent with those in previous studies however these differences between preterm and term groups were not consistent with those in previous studies. In previous studies, it was found that the mean absolute error rate percentage in term gestation varied between 6 and $11 \%$ while this rate was higher in preterm gestation. Moreover, fetal weight estimation in those with SGA and LGA is more suc- cessful and accurate than in newborns with normal birth weight $(10,11)$. In their study conducted in 2004, Kurmanavicius et al. concluded that the absolute percentage error for term gestation was $6.2 \%$ while this rate was found to be higher in preterm gestation and reached $10 \%$ as the gestational week decreased (10). They concluded that the absolute percentage error in newborns weighed between 2500 and 4000 $\mathrm{g}$ was $6 \%$ whereas this rate reached more than $10 \%$ in those weighed below $2500 \mathrm{~g}$ with SGA. This increase was also detected in those above $4000 \mathrm{~g}$ or with LGA even though the increase was less prominent (8-9\%). Moreover, in their study, the mean estimated fetal weight was higher than the real birth weight in the preterm delivery and SGA groups, which was found to be lower in our present study (10). The reason behind this discrepancy may be due to that only the Hadlock formula was used in our study whereas Kurmanavicius et al. used formulas that measure higher than the Hadlock formula such as Shepard, Campbell, and Merz formulas in their study (10). In their study with 1941 patients in 2008, Siemer et al. concluded that the percentage error and the absolute percentage error were found to be lower in term deliveries and AGA fetuses compared to preterm deliveries and SGA fetuses (the percentage error: $-3.46 \pm 11.15$ vs. $-3.57 \pm 11.60$, respectively; and the absolute percentage error: $8.80 \pm 7.67$ vs. $9.49 \pm 7.52$, respectively) (11). In our study, the percentage error and the absolute percentage error were found to be higher in term deliveries than preterm deliveries (respectively, -8.11 (-49.52 -(20.44)), $-3.30(-46.36-(43.38)), p=0.001,10.59(0-(49.52)), 8.86(0-$ (46.36)), $p=0.01)$ whereas the accurate estimation rate was found to be lower in term gestation (respectively, 145/260 (55.8\%), 527/822 (64.1\%), $p=0.016)$. The reason behind the discrepancy from previous studies may be due to that our study had more preterm deliveries and that these patients included patients not only with SGA but also patients with AGA, which was not the case in the term delivery group. In other words, the fact that term patients are only composed of newborns with SGA may have caused a higher percentage error rate regardless of their being term. No statistically significant difference was found between the error percentage, the absolute percentage error, and the accuracy rate in newborns weighed between $500 \mathrm{~g}-1500 \mathrm{~g}$ and $1501 \mathrm{~g}-2500 \mathrm{~g}$. The reason is due to that the classification only by birth weight, without considering the gestational week, may have hampered the homogenous distribution of patient groups. Therefore, newborns with the same birth weight at different gestational weeks may have been assessed within the same group. This may have caused newborns with SGA and AGA to be assessed in the same group.

Various parameters were considered to affect fetal weight estimation accuracy in the literature. Heer et al., Mills et al., and Scott et al. (12-14) demonstrated in their studies that gestational age at birth did not have a significant impact on fetal weight estimation accuracy. In our study, we detected that gestational age at birth did have an impact on fetal weight es- 
timation accuracy. Pregnant women between 24 and 27 GWs were included in these three studies (12-14) whereas our study was conducted with pregnant women between 24 and 41 GWs. This may have provided an advantage in our study in terms of the effect of gestational age at birth on fetal weight estimation accuracy.

The impact of birth weight on fetal weight estimation is controversial. In their studies, Heer et al., Mills et al., Kaaij et al., and Meyer et al. $(12,13,15,16)$ detected that birth weight did not have any impact on fetal weight estimation accuracy. On the contrary, Melamed et al., and Townsend et al. (17-19) detected in their studies that birth weight had an impact on fetal weight estimation accuracy, as found in our present study.

The impact of fetal gender in determining fetal weight estimation accuracy is also controversial. Melamed et al. (17) and Siemer et al. (20) observed in their studies that fetal weight estimation accuracy was lower in female fetuses and that fetal gender had an impact on fetal weight estimation accuracy whereas Heer et al., and Mills et al. observed that fetal gender did not have any impact on fetal weight estimation accuracy, in accordance with our study $(12,13)$.

In most of the studies in the literature, the longest duration of time between ultrasonographic measurement and birth was 7 days. In studies in which the longest duration of time between ultrasonographic measurement and birth was 14 days, Kaaij et al. (15) concluded that the duration between measurement and birth did not have any impact on fetal weight estimation accuracy while Scott et al. (14) found that there was an impact on fetal weight estimation accuracy. In their study, Heer et al. (12) categorized the cases in 2 groups as (0-7) days and (8-14) days based on the duration between measurement and birth. In the 8-14 days' group, they found that the error rate was higher. In our study, we determined the upper limit of duration of time between measurement and birth as 7 days, as was the case in most studies. Accordingly, we demonstrated that the duration between measurement and birth had an impact on fetal weight estimation accuracy.

The impact of fetal presentation on fetal weight estimation accuracy is contentious. Heer et al., Mills et al., Edwards et al., and Ragosch et al. demonstrated that fetal presentation did not have any impact on fetal weight estimation accuracy $(12,13,21,22)$. Melamed et al. and Chauhan et al. showed in their studies that the error rate was higher in pregnancies with breech presentation $(17,23)$. In our study, the fetal presentation was found to have an impact on fetal weight estimation accuracy in linear regression analysis but not in multiple regression analysis. This makes us think that gestational age at birth and birth weight intersect the role of fetal presentation in determining fetal weight estimation accuracy in multiple regression analysis.

Heer et al., Mills et al., Scott et al., Meyer et al., Townsend et al., Durbin et al., Shamley et al., Toohey et al., and Valea et al. demonstrated that amniotic fluid and membrane rupture did not have any impact on fetal weight estimation accuracy (1214,16,19,24-27). In their studies, Edward et al. detected that oligohydramnios $(\mathrm{AFI}<5 \mathrm{~cm})$ and membrane rupture caused low birth weight were associated with an underestimation of the fetal weight (21). However, in their study, only 20 women had oligohydramnios and premature rupture of membranes. We think that the role of oligohydramnios and membrane rupture in fetal weight estimation accuracy should not be determined with such a small sample size. In our study, the presence of oligohydramnios and premature rupture of membranes was found to be effective in fetal weight estimation accuracy in linear regression analysis whereas they did not have any impact on fetal weight estimation accuracy in multiple regression analysis. Presumably, parameters that were found to be effective in multiple regression analysis including gestational age at birth, birth weight, the onset of labor, and the duration of time (days) between measurement and birth may mask the impact of amniotic fluid.

Faschingbauer et al. demonstrated that the inaccurate estimation rate by ultrasonographic measurement during labor was high and that it was lower than the actual birth weight (28). In parallel with the above-mentioned study, in our study, we demonstrated that the error rate of fetal weight estimation accuracy was lower in patients that are not in labor. Moreover, we detected that labor was effective in both linear and multiple regression analyses.

Heer et al., Scott et al., and Shamley et al. demonstrated in their studies that placental location did not have an impact on fetal weight estimation accuracy $(12,14,25)$, as we also observed in our study.

Heer et al., Scott et al., Edwards et al., Shamley et al., Farrell et al., and Field et al. demonstrated in their studies that BMI did not have an impact on fetal weight estimation accuracy $(12,14,21,25,29,30)$, as we did in our study.

The percentage error and the absolute percentage error are higher in those with SGA than in those with AGA fetuses. In the preterm delivery group, unexpected results were achieved compared to those with SGA fetuses. The reason for that was that the term delivery group was entirely composed of those with SGA fetuses whereas the presence of AGA fetuses, as well as SGA fetuses, may have affected the results in the preterm delivery group. Even though many predictive parameters in ultrasonographic fetal weight estimation accuracy were found in linear regression, the impact of some of these parameters disappeared in multiple regression analysis. The four significant predictive parameters were gestational age at birth, birth weight, examination after the onset of labor, and the duration between measurement and birth. The most important ones were found to be birth weight and gestational age at birth. 
Acknowledgment: This manuscript is the result of the MD thesis of Nevin Tuten. As our mentor, we would like to thank Altay Gezer

Competing interests: The authors declare that they have no competing interests.

Funding: None

Ethics approval and consent to participate: This study was authorized by the Ethics Committee of the Istanbul UniversityCerrahpasa, Cerrahpasa Medical Faculty (06.11.2014, 02235911). Consent to use the data was obtained for this retrospective study, and the study was conducted in accordance with Helsinki's declaration.

Availability of data and materials: The data supporting this study is available through the corresponding author upon reasonable request.

Authors' contributions: Altay Gezer and Nevin Tuten raised the presented idea. Altay Gezer, Nevin Tuten, and Abdullah Tuten designed the study. Onur Guralp and Koray Gok conducted the analyses. Nevin Tuten, Abdullah Tuten, Onur Guralp, and Koray Gok developed the first draft of the manuscript. All authors contributed to the writing of the paper, and have read and approved the final manuscript.

\section{References}

1. McIntire DD, Bloom SL, Casey BM, Leveno KJ. Birth weight in relation to morbidity and mortality among newborn infants. N Engl J Med. 1999;340(16):1234-8. Doi: 10.1056/NEJM199904223401603.

2. Pilliod RA, Cheng YW, Snowden JM, Doss AE, Caughey $\mathrm{AB}$. The risk of intrauterine fetal death in the small-forgestational-age fetus. Am J Obstet Gynecol. 2012;207 (4): 318.e1-6. Doi: 10.1016/j.ajog.2012.06.039.

3. Warsof SL, Gohari P, Berkowitz RL, Hobbins JC. The estimation of fetal weight by computer-assisted analysis. Am J Obstet Gynecol. 1977;128(8):881-92. Doi: 10.1016/0002-9378(77)90058-8.

4. Shepard MJ, Richards VA, Berkowitz RL, Warsof SL, Hobbins JC. An evaluation of two equations for predicting fetal weight by ultrasound. Am J Obstet Gynecol. 1982; 142(1):47-54. Doi: 10.1016/s0002-9378(16)32283-9.

5. Hadlock FP, Harrist RB, Fearneyhough TC, Deter RL, Park SK, Rossavik IK. Use of femur length/abdominal circumference ratio in detecting the macrosomic fetus. Radiology. 1985;154(2):503-5. Doi: 10.1148/radiology. 154.2.3880915.

6. Hadlock FP, Harrist RB, Sharman RS, Deter RL, Park SK. Estimation of fetal weight with the use of head, body, and femur measurements--a prospective study. Am J Obstet Gynecol. 1985;151(3):333-7. Doi: 10.1016/00029378(85)90298-4.

7. Stefanelli S, Groom KM. The accuracy of ultrasound-estimated fetal weight in extremely preterm infants: a comparison of small for gestational age and appropriate for gestational age. Aust N Z J Obstet Gynaecol. 2014;54(2):
126-31. Doi: 10.1111/ajo.12198.

8. Huber C, Zdanowicz JA, Mueller M, Surbek D. Factors influencing the accuracy of fetal weight estimation with a focus on preterm birth at the limit of viability: a systematic literature review. Fetal Diagn Ther. 2014;36(1):1-8. Doi: $10.1159 / 000358518$.

9. Kiserud T, Piaggio G, Carroli G, Widmer M, Carvalho J, Neerup Jensen L, et al. The World Health Organization fetal growth charts: a multinational longitudinal study of ultrasound biometric measurements and estimated fetal weight. PLoS Med. 2017;14(1): e1002220. Doi: 10.1371/ journal.pmed.1002220.

10. Kurmanavicius J, Burkhardt T, Wisser J, Huch R. Ultrasonographic fetal weight estimation: accuracy of formulas and accuracy of examiners by birth weight from 500 to 5000 g. J Perinat Med. 2004;32(2):155-61. Doi: 10.1515/JPM.2004.028.

11. Siemer J, Egger N, Hart N, Meurer B, Müller A, Dathe O, et al. Fetal weight estimation by ultrasound: comparison of 11 different formulae and examiners with differing skill levels. Ultraschall Med. 2008;29(2):159-64. Doi:10. 1055/s-2007-963165.

12. Heer IM, Kumper C, Vogtle N, Muller-Egloff S, Dugas M, Strauss A. Analysis of factors influencing the ultrasonic fetal weight estimation. Fetal Diagn Ther. 2008; 23(3): 204-10. Doi: 10.1159/000116742.

13. Mills MD, Nageotte MP, Elliott JP, Crade M, Dorchester W. Reliability of ultrasonographic formulary in the prediction of fetal weight and survival of very-low-birthweight infants. Am J Obstet Gynecol. 1990;163(5 Pt 1): 1568-74. Doi: 10.1016/0002-9378(90)90629-1.

14. Scott F, Beeby P, Abbott J. Accuracy of estimated fetal weight below 1,000 g. Aust N Z J Obstet Gynaecol. 1996; 36(2):129-32. Doi: 10.1111/j.1479-828x.1996.tb 03267.x.

15. Kaaij MW, Struijk PC, Lotgering FK. Accuracy of sonographic estimates of fetal weight in very small infants. Ultrasound Obstet Gynecol. 1999;13(2):99-102. Doi: 10. 1046/j.1469-0705.1999.13020099.x.

16. Meyer WJ, Font GE, Gauthier DW, Myles TD, Bieniarz A, Rodriguez A. Effect of amniotic fluid volume on ultrasonic fetal weight estimation. J Ultrasound Med. 1995; 14(3):193-7. Doi: 10.1046/j.1469-0705.1999.13020099.x.

17. Melamed N, Ben-Haroush A, Meizner I, Mashiach R, Glezerman M, Yogev Y. Accuracy of sonographic weight estimation as a function of fetal sex. Ultrasound Obstet Gynecol. 2011;38(1):67-73. Doi: 10.1002/uog.8914.

18. Melamed N, Yogev Y, Meizner I, Mashiach R, Bardin R, Ben-Haroush A. Sonographic fetal weight estimation: which model should be used? J Ultrasound Med. 2009; 28(5):617-29. Doi: 10.7863/jum.2009.28.5.617.

19. Townsend RR, Filly RA, Callen PW, Laros RK. Factors affecting prenatal sonographic estimation of weight in extremely low birthweight infants. J Ultrasound Med. 1988; 
7(4):183-7. Doi: 10.7863/jum.1988.7.4.183.

20. Siemer J, Wolf T, Hart N, Schrauder M, Meurer B, Goecker $\mathrm{T}$, et al. Increased accuracy of fetal weight estimation with a gender-specific weight formula. Fetal Diagn Ther. 2008;24(4):321-6. Doi: 10.7863/jum.1988. 7.4.183.

21. Edwards A, Goff J, Baker L. Accuracy and modifying factors of the sonographic estimation of fetal weight in a high-risk population. Aust N Z J Obstet Gynaecol. 2001; 41(2):187-90. Doi: 10.1111/j.1479-828x.2001.tb01206.x.

22. Ragosch V, Entezami M, Hundertmark S, Mutz A, Becker $\mathrm{R}$, Weitzel H. Accuracy of ultrasound weight assessment-comparison of vertex vs. breech presentation. Ultraschall Med. 1997;18(1):19-25. Doi: 10.1055/s-2007-1000510.

23. Chauhan SP, Magann EF, Naef RW $3^{\text {rd }}$, Martin JN Jr, Morrison JC. Sonographic assessment of birth weight among breech presentations. Ultrasound Obstet Gynecol. 1995;6(1):54-7. Doi:10.1046/j.1469-0705.1995.0601 0054.x.

24. Durbin SA, Lee CW, Parker VG. The effect of amniotic fluid index on the accuracy of sonographic estimated fetal weight. J Diagnostic Med Sonography. 2005;21(4):32935. Doi: $10.1177 / 8756479305278267$.

25. Shamley K, Landon MB. Accuracy and modifying factors for ultrasonographic determination of fetal weight at term. Obstet Gynecol. 1994;84(6):926-30. PMID:7970 471.

26. Toohey JS, Lewis DF, Harding JA, Crade M, Asrat T, Major CA, et al. Does amniotic fluid index affect the accuracy of estimated fetal weight in preterm premature rupture of membranes? Am J Obstet Gynecol. 1991;165(4 Pt 1):1060-2. Doi: 10.1016/0002-9378(91)90470-c.

27. Valea FA, Watson WJ, Seeds JW. Accuracy of ultrasonic weight prediction in the fetus with preterm premature rupture of membranes. Obstet Gynecol. 1990;75(2):183-5. PMID: 2405317.

28. Faschingbauer F, Dammer U, Raabe E, Schneider M, Faschingbauer C, Schmid M, et al. Intrapartum sonographic weight estimation. Arch Gynecol Obstet. 2015; 292(4):805-11. Doi: 10.1007/s00404-015-3720-3.

29. Farrell T, Holmes R, Stone P. The effect of body mass index on three methods of fetal weight estimation. BJOG. 2002;109(6):651-7. Doi: 10.1111/j.1471-0528.2002.01 249.x.

30. Field NT, Piper JM, Langer O. The effect of maternal obesity on the accuracy of fetal weight estimation. Obstet Gynecol. 1995;86(1):102-7. Doi: 10.1016/0029-7844(95) 00096-A. 